\title{
ISLAM RAHMATAN LIL ALAMIN FROM SOCIAL AND CULTURAL PERSPECTIVE
}

\author{
ISLAM RAHMATAN LIL ALAMIN DALAM \\ PERSPEKTIF SOSIAL DAN BUDAYA
}

\author{
P-ISSN: 2085-5818 | E-ISSN: 2686-2107 \\ https://uia.e-journal.id/alrisalah/article/view/1376 \\ DOI: 10.34005/alrisalah.v12i2.1376
}

Naskah Dikirim: 08-06-2021 Naskah Direview: 10-06-2021 Naskah Diterbitkan: 17-06-2021

\author{
Khairan Muhammad Arif \\ UIN Syarif Hidayatullah Jakarta \\ khairan.arif@uinjkt.ac.id
}

\begin{abstract}
Rahmatan Lil Alamin's Islamic is a general purpose of Islam (Maqashid Am Li Syariah). All the teachings of Islam boil down to Maslahat, compassion and peace of the world, beings and all human beings. The purpose of this study is to uncover the characteristics and main objectives of Islamic teachings that rahmatan lil alamin in the social and cultural life of modern humans. The method used in this study is the Method of Literature Study and analysis of scientific references related to Islam rahmatan lil alamin in social and cultural perspectives. the result of this kajia is that the implementation of Rahmatan Lil alamin values in social life can be seen in the educational life of schools, communities, places of worship and workplaces and mass media. The implementation of Rahmatan Lilalamin values in budya life, can be seen from the Development of Science, Language, Ideology and Customs.
\end{abstract}

Keywords: Grace, Nature, Social, Culture.

Abstrak: Islam Rahmatan Lil Alamin adalah tujuan umum Islam (Maqashid Am Li Syariah). Seluruh ajaran Islam bermuara pada Maslahat, kasih sayang dan kedamaian dunia, makhluk dan seluruh manusia. Tujuan kajian ini adalah menyingkap karakteristik dan tujuan utama ajaran Islam yang rahmatan lil alamin dalam kehidupan sosial dan budaya manusia modern. Metode yang digunakan dalam kajian ini adalah metode Kajian Pustaka dan analisa referensi-referensi ilmiah terkait Islam rahmatan lil alamin dalam perspektif Sosial dan Budaya. hasil dari kajia ini adalah bahwa Implementasi Nilai-nilai Rahmatan Lil alamin dalam kehidupan social dapat dilihat dalam kehidupan pendidikan sekolah, masyarakat, Tempat Ibadah dan tempat kerja serta Media Massa. Adapun Implementasi Nilai-nilai Rahmatan Lilalamin dalam Kehidupan budya, dapat dilihat dari Perekembangan Ilmu pengetahuan, Bahasa, Ideologi dan adat Istiadat.

Kata Kunci: Rahmat, Alam, Sosial, Budaya

Khairan Muhammad Arif | Islam Rahmatan Lil Alamin Dalam Perspektif Sosial Dan Budaya 


\section{A. PENDAHULUAN}

Salah satu keunggulan Islam dibanding dengan agama lain di dunia, adalah sifat dan karakternya yang Rahmatan Lil Alamin.. Islam adalah agama yang universal dan global, dia adalah agama dan syari'at untuk seluruh manusia, dia adalah agama dan syari'at untuk seluruh alam dan dia adalah agama dan syari'at untuk seluruh Jin dan Manusia.

Makna rahmatan lil alamin selain bahwa Islam bersifat universal, global dan menyeluru untuk semua manusia di dunia, makna rahmatan lil alamin juga menetapkan bahwa Islam adalah agama dan syari'at yang penuh dengan kasih sayang, cinta, persaudaraan dan kedamaian.

Islam tidak pernah mengajarkan permusuhan dan kebencian, islam tidak memiliki ajaran dan syari'at destruktif dan kejahatan, bahkan sebaliknya semua ajaran dan syari'at Islam bertujuan untuk melahirkan dan mewujudkan maslahat abadi bagi manusia. Oleh karenanya para Ulama telah menetapkan bahwa Syari'at Islam memiliki maqashid (tujuan) yang abadi seperti memelihara akal manusia, keturunan, harta, agama dan harga dirinya. Dari sinilah Islam kemudian disebut agama yang rahmatan lul alamin.

Hampir semua surat dan ayat dalam Al-Qur'an bicara tentang manusia, asal dan karakternya bahkan kemana akan berakhir kehidupannya. Tidak ada kitab suci dan buku ilmiah di dunia yang paling tinggi, lengkap dan komprehensif membahas tenang manusia selain AlQur'an. Oleh karena itu Islam adalah agama yang paling mengerti tentang manusia dan paling tinggi penghargaannya kepada manusia dan kemanusiaan, baik kehidupan ideology, politik, social, budaya, ekonomi dan sebagainya.

\section{B. METODOLOGI}

Metode yang digunakan dalam kajian ini adalah metode Kajian Pustaka dan analisa referensi-referensi ilmiah terkait Islam rahmatan lil alamin dalam perspektif Sosial dan Budaya. Hasil dari kajia ini adalah bahwa Implementasi Nilai-nilai Rahmatan Lil alamin dalam kehidupan social dapat dilihat dalam kehidupan pendidikan sekolah, masyarakat, Tempat lbadah dan tempat kerja serta Media Massa. Adapun Implementasi Nilai-nilai Rahmatan Lilalamin dalam Kehidupan budya, dapat dilihat dari Perekembangan IImu pengetahuan, Bahasa, Ideologi dan adat Istiadat. 


\section{PEMBAHASAN}

\section{Hakikat Islam Rahmatan Lil Alamin}

Kalimat ini terdiri dari dua kata, pertama: Rahmat yang diambil dari kata ر رحم yang bermakna Rahim wanita, ketika disebut رمة maka artinya adalah "kasih sayang dan kelembutan yang diiringi berbuat baik kepada yang disayangi"'1. Kata رحة disebutkan sebanyak 25 ayat dalam Al-Qur'an dengan tema yang berbeda-beda, yang menunjukkan bahwa pentingnya dan tingginya kedudukan rahmat dalam ajaran Islam.

Kedua kata للمالمين artinya adalah "untuk alam-alam. At-Thabari berkata: للعالمين adalah jamak dari عالم yama bagi jenis-jenis umat atau bangsa, setiap jenis suku bangsa disebut "Alam", karenanya manusia juga disebut alam dan setiap manusia disuatu zaman disebut alam. Jin disebut alam dan semua jenis makhluk disebut alam, setiap jenis makhluk ini disebut alam pada zamannya"2.

Ibnu Katsir ketika menafsirlkan rahmatan lil alamin dalam QS. AlAnbiya: 107 berkata: "Muhammad saw adalah rahmat bagi semua manusia, siapa saja yang menerimanya, berarti mereka mnesyukuri nikmat besar ini, yaitu kasih sayang dan mereka akan bahagia di dunia dan akhirat. Sebaliknya siapa yang menolaknya maka mereka akan sengsara di dunia dan akhirat. Oleh karena itu Nabi saw bersabda: 'Aku tidaklah diutus sebagai tukan laknat, tapi akau diutus untuk menjadi rahmat" (HR. Muslim). Dalam riwayat lain Nabi bersabda: "Sesungguhnya aku adalah rahmat yang memberi hidayah pada manusia" (HR. At-Thabrani, Ad-Darimi dan AlHakim. Dishahihkan oleh At-thabrani dan Al-Hakim) ${ }^{3}$. Imam As-Syatibi berkata: "Tidak ada yang menyangkal Ar-Razi dan ulama lainnya, bahwa tujuan utama syari'ah, adalah mewujudkan maslahat bagi manusia ${ }^{4}$. Allah SWT mengutus para Nabi dan Rasul untuk mewujudkan tujuan tersebut

\footnotetext{
1 Ar-Raghib Al-Ashfahani, Mu'jam Mufradat Li Alfadzil Qur'an, (Beirut: Daar Al-Kutub AlIlmiyah, 2013) hal 215

2 Ibnu Jarir At-Thabari, Tafsir At-Thabari, vol 1 (Kairo: Maktabah At-Taufiqiyah, 2004), hal 124

3 Ismail Ibnu Katsir, Tafsir Ibnu Katsir, vol 3, (Beirut: Daar Al-Fikr, 1994), hal 385

${ }^{4}$ Adapaun tujuan pembebanan hukum kepada para mukallaf, menurut Imam Abu Hamid Al-Ghazali dan Imam As-Syatibi, dan telah disepakati oleh para ulama lainnya adalah untuk memelihara dan menjaga lima hal asasi (Dharuriyatul Khamsah) dalam kehidupan mukallaf. Pertama: Menjaga agama, kedua: Menjaga Jiwa, ketiga: menjaga akal, keempat: menjaga keturunan dan kelima: menjaga harta. Lihat Abu Hamid Al-Ghazali, Al-Mustashfa min IImi Al-Ushul, (Riyadh: Daar Al-Mihan, tt), hal 328 dan As-Syatibi, Al-Muwafaqat, vol 2, hal 2
}

Khairan Muhammad Arif | Islam Rahmatan Lil Alamin Dalam Perspektif Sosial Dan Budaya 
yaitu Menjadi Rahmat bagi Alam Semesta. Firman Allah: "Dan Kami tidak mengutus engkau (Muhammad) melainkan untuk (menjadi) rahmat bagi seluruh alam”. (QS. Al-Anbiya: 108) ${ }^{5}$.

Sayid Qutb saat menafsirkan Surat Al-Anbiya: 107, mengatakan bahwa makna Rahmatan Lil alamin adalah petunjuk bagi semua manusia, mengajak semua manusia kepada petunjuk, tapi kepada mereka yang siap dan mau menerima petunjuk itu, walaupun kasih sayang diberikan oleh Allah swt orang beriman dan yang tidak beriman" 6. Zaid Al-lyash menjelaskan Islam rahmatan lil alamin adalah bahwa Nabi Muhammad saw membawa konsep dan budaya baru tentang kemanusiaan yaitu konsep dan budaya "Cinta dan kasih sayang" yang berlaku bagi seluruh manusia, di saat manusia ketika Nabi diutus oleh Allah swt dalam kondisi budaya permusuhan dan kebencian antara satu bangsa dengan yang lain ${ }^{7}$.

Jadi Islam rahmatan lil alamin adalah Islam yang mengajarkan dan menyebarkan budaya dan tsaqafah cinta, kedamaian dan kasih sayang, kelembutan dan penghormatan kepada seluruh manusia, memberi petunjuk dan hidayah kepada mereka di seluruh dunia, melewati batas-batas kesukuan, kebangsaan, Negara dan geografis ${ }^{8}$.

\section{Prinsip-Prinsip Islam Rahmatan Lil Alamin}

Islam Rahmatan lilalamin memiliki prinsip-prinsip yang menjadi ciri khas Islam yang menghadirkan cinta kasih dan kedamaian bagi dunia. Ada beberapa prinsip Islam Rahmatan Lilalamin menurut kajian komprehensif para Ulama diantaranya adalah:

\section{Berperikemanusiaan (al-Insaniyah)}

Kemanusiaan atau Insaniyah maksudnya adalah, bahwa Islam sesuai dan selalu mengakomodir semua kebutuhan dan karakter manusia. Pembebanan ibadah, hukum, perintah dan larangan dalam syariah Islam pasti sesuai dan selaras dengan kemampuan dan kebutuhan manusia. Tidak ada ajaran Islam yang bertentangan dengan kemanusiaan dan tidak ada syariah yang tidak mengandung maslahat manusia, karena syariah Islam tidak diciptakan oleh Allah dengan sia-sia, hampa dan tanpa manfaat dan tujuan. Allah berfirman "Dan Kami tidak menciptakan langit dan bumi

\footnotetext{
5 Lihat Abu Ishaq As-Syatibi, Al-Muwafaqat fii Ushul As-Syariah, Kairo: al- maktabah attaufiqiyah, 2003, Vol 2, hal 2 dan Yusuf Al-Qardhawi dalam Hajatul Basyariyah Ilaa Risalah Al-Hadahriyah Liummatina, hal 70

${ }^{6}$ Lihat Sayid Qutb, Fi Dzilal Al-Qur'an, vol 4, (Kairo: Dar Syuruq, 1995), hal 2401

7 Khairan Muhammad Arif, Moderasi Islam, Telaah Komprehensif Pemikiran Wasathiyah Islam, (Jakarta: Ikadi Press, 2020), hal 102

8 Khairan Muhammad Arif, Moderasi Islam, hal 102
}

Khairan Muhammad Arif | Islam Rahmatan Lil Alamin Dalam Perspektif Sosial Dan Budaya 
dan apa yang ada di antara keduanya dengan sia-sia. Itu anggapan orangorang kafir, maka celakalah orang-orang yang kafir itu karena mereka akan masuk neraka”. (QS. Shad: 27). ${ }^{9}$

Insaniyah dalam Islam bermakna bahwa tidak ada ajaran di dunia ini yang lebih lengkap, sempurna dan komprehensif menjelaskan tentang hakikat kehidupan manusia selain syariah Islam. Tidak ada kitab suci dan ideologi di dunia ini yang lebih unggul dan futuristic menjelaskan kehidupan manusia, baik sumber materi penciptaannya, proses terjadinya, karakteristiknya, kewajiban-kewajibannya dan kemana akan dikembalikan kehidupan mereka selanjutnya, selain Al-Qur'an yang menjadi sumber utama syariah, dan dijelaskan dalam surat yang bernama Al-Insan (manusia). Allah berfirman: "Bukankah pernah datang kepada manusia waktu dari masa, yang ketika itu belum merupakan sesuatu yang dapat disebut?. Sungguh, Kami telah menciptakan manusia dari setetes mani yang bercampur yang Kami hendak mengujinya (dengan perintah dan larangan), karena itu Kami jadikan dia mendengar dan melihat. Sungguh, Kami telah menunjukkan kepadanya jalan yang lurus; ada yang bersyukur dan ada pula yang kufur". (QS. Al-Insan: 1-3)

Insaniyah syariah Islam juga bermakna bahwa ajaran, pedoman dan panduan hidup manusia, yang diturunkan oleh Allah untuk manusia dan lingkungannya, disesuaikan dengan akal, hati, emosional, fitrah dan fisiknya. Sehingga tidak ada ajaran Islam baik konsep maupun implementasinya yang tidak dapat dimengerti, dirasakan dan diamalkan oleh manusia. Seluruh perintah dan larangannya telah dimudahkan dicocokkan dan dikoneksikan oleh Allah SWT dengan kemampuan manusia dan kemanusiaannya. Allah berfirman: "Allah tidak membebani seseorang melainkan sesuai dengan kesanggupannya. Dia mendapat (pahala) dari (kebajikan) yang dikerjakannya dan dia mendapat (siksa) dari (kejahatan) yang diperbuatnya. (Mereka berdoa), "Ya Tuhan kami, janganlah Engkau hukum kami jika kami lupa atau kami melakukan kesalahan. Ya Tuhan kami, janganlah Engkau bebani kami dengan beban yang berat sebagaimana Engkau bebankan kepada orang-orang sebelum kami. Ya Tuhan kami, janganlah Engkau pikulkan kepada kami apa yang tidak sanggup kami memikulnya. Maafkanlah kami, ampunilah kami, dan rahmatilah kami. Engkaulah pelindung kami, maka tolonglah kami menghadapi orang-orang kafir."(QS. Al-Baqarah: 286)

Insaniyah ajaran Islam juga bermakna bahwa semua tujuan (maqashid), manfaat dan hikmah syariah dalam rangka mewujudkan kebaikan, rahmat dan kemaslahatan (mashlahah) bagi manusia seluruhnya dan menghindarkan manusia dan lingkungannya dari kejahatan, kezaliman

${ }^{9}$ Lihat Khairan Muhammad Arif, Moderasi Islam, hal 220

Khairan Muhammad Arif | Islam Rahmatan Lil Alamin Dalam Perspektif Sosial Dan Budaya 
dan kerusakan (mafsadat) di dunia dan akhirat. Tidak ada ajaran dan nilainilai syariah sedikitpun yang bertentangan dengan maslahat manusia dan lingkungannya. Allah berfirman: "Dan dalam syariah qisas itu ada (jaminan) kehidupan bagimu, wahai orang-orang yang berakal, agar kamu bertakwa". (QS. Al-Baqarah: 179). "Dan Kami tidak mengutus engkau (Muhammad) melainkan untuk (menjadi) rahmat bagi seluruh alam". (QS. Al-Anbiya: 108).

Dalam riwayat Abu Shaleh, Nabi Saw bersabda: "Wahai manusia, sesuangguhnya aku adalah rahmat yang memberi petunjuk" (HR. AtThabrani, Ad-Darimi dan Al-Hakim. Dishahihkan oleh At-thabrani dan AlHakim). Dalam hadits lain riwayat Abu Hurairah RA, Nabi SAW besabda: "Sesungguhnya aku tidak diutus menjadi tukang laknat, melainkan aku diutus untuk menjadi rahmat" (HR. Muslim dan Ahmad).

\section{Mendunia (al-alamiyah)}

Yang dimaksud dengan mendunia atau global (al-alamiyah) adalah, bahwa syariah Islam bersifat mendunia, tidak dibatasi oleh geografi wilayah tertentu, suku, ras dan bangsa tertentu atau iklim serta geopolitik tertentu. Syariah Islam berlaku untuk seluruh alam dan seluruh manusia yang mau menerimanya. Tidak ada perbedaan antara tujuan dan ajaran syariah di Arab dengan diluar Arab atau sebaliknya, tidak ada perbedaan keyakinan umat Islam terhadap syariah bahwa dia bersumber dari Allah dan untuk maslahat seluruh alam dimanapun mereka berada ${ }^{10}$.

Tidak ada perbedaan pengamalan pokok-pokok syariah (ushul) kecuali dalam masalah cabang dan rantinya (furuiyah) dimanapun umat Islam berada di kolong dunia ini. Tidak ada perbedaan diantara umat Islam dunia dalam pelaksanaan ibadah, muamalah, hukum dan moralitasnya.

Globalisasi (alamiyah) syariah Islam mengajarkan persaudaraan dunia antara manusia lintas golongan-golongan, suku bangsa dan bahasanya. Syariah Islam mengajarkan tolong menolong global antara manusia dan memelihara lingkungannya. Sebaliknya syariah Islam mengharamkan permusuhan antara manusia dimanapun mereka berada di dunia ini tanpa memandang suku, ras, agama, warna kulit dan bangsanya selama tolong menolong itu untuk kebaikan dan maslahat manusia. Allah berfirman:

“Wahai manusia! Sungguh, Kami telah menciptakan kamu dari seorang laki-laki dan seorang perempuan, kemudian Kami jadikan kamu berbangsabangsa dan bersuku-suku agar kamu saling mengenal. Sesungguhnya yang paling mulia di antara kamu di sisi Allah ialah orang yang paling

${ }^{10}$ Khairan Muhammad Arif, Moderasi Islam, hal 222

Khairan Muhammad Arif | Islam Rahmatan Lil Alamin Dalam Perspektif Sosial Dan Budaya 
bertakwa. Sungguh, Allah Maha Mengetahui, Maha Teliti. (QS. Al-Hujurat: 13).

"Dan tolong-menolonglah kamu dalam (mengerjakan) kebajikan dan takwa, dan jangan tolong-menolong dalam berbuat dosa dan permusuhan. Bertakwalah kepada Allah, sungguh, Allah sangat berat siksaan-Nya". (QS. Al-Maidah: 2).

Globalisasi syariah Islam bermakna bahwa syariah Islam untuk diperuntukkan untuk seluruh manusia dan seluruh alam semesta, rahmat globalisasi Islam adalah rahmat seluruh alam dan seluruh lingkungan manusia. Negeri Islam adalah semua negeri yang telah dan akan dikumandangkan Laa Ilaaha Illallah (tidak ada Tuhan selain Allah). Karena syariah ini berasal dari Tuhan semesta Alam, Allah Subhanahu wata'ala. Oleh karenanya Nabi umat Islam adalah Nabi dan Rasul untuk semua manusia dan seluruh alam semesta.

"Dan Kami tidak mengutus engkau (Muhammad) melainkan untuk (menjadi) rahmat bagi seluruh alam". (QS. Al-Anbiya: 108). "Dan Kami tidak mengutusmu wahai Muhammad kecuali untuk seluruh manusia” (QS. )

\section{Komprehensif (as-syumul)}

Komprehensif atau syumul adalah keseluruhan atau totalitas ajaran syariah Islam, meliputi seluruh atau semua aspek kehidupan manusia di dunia dan akhirat. Islam tidak menerima dan mengenal pembagian atau pembatasan ajarannya pada dimensi atau bidang tertentu dalam kehidupan manusia, karena syariah Islam berasal dan bersumber dari Tuhan yang Maha Sempurna Allah SWT. Ajaran Islam adalah syariah yang mengatur dan membimbing kehidupan manusia di dunia dan akhirat, bahkan aspek ajaran syariah yang paling tinggi dan besar adalah aspek akhirat yang dikenal dengan aspek ibadah. Aspek kedua adalah muamalah yang mengatur kehidupan manusia dengan manusia dan hubungan manusia dengan lingkunngannya. Inilah karakteristik syariah Islam yang komprehensif secara vertikal dan horizontal. Firman Allah: "Pada hari ini telah Aku sempurnakan agamamu untukmu, dan telah Aku cukupkan nikmat-Ku bagimu, dan telah Aku ridhai Islam sebagai agamamu". (QS. AlMaidah: 3$)^{11}$

Syariah Islam dalam bentuk Ibadah membimbing manusia dalam berinteraksi dengan Allah SWT secara sempurna dan totalitas, tidak menyisakan sedikitpun dari dimensi dirinya, waktunya, pikirannya, akalnya, hatinya, emosional, psikologis, jiwanya, fisiknya atau lahir dan bathin

11 Khairan Muhammad Arif, Moderasi Islam, hal 223

Khairan Muhammad Arif | Islam Rahmatan Lil Alamin Dalam Perspektif Sosial Dan Budaya 
kecuali hanya untuk Allah SWT ${ }^{12}$. Inilah pengertian dan hakikat ibadah dalam syariah Islam. Allah berfirman: "katakana wahai Muhammad sesusngguhnya shalatku, manasikku hidup dan matiku hanya untuk Allah Tuhan semesta alam" (QS.).

Demikian pula bahwa ajaran Islam dalam bentuk muamalah mengatur dan membimbing secara sempurna dan lengkap semua dimensi interaksi hidup antar manusia dan lingkungannya. Mumalah Islamiyah adalah muamalah komprehensif dan menyeluruh, meliputi semua aspek politik, ekonomi, budaya, sosial, pendidikan keluarga, hankam, teknologi dan semua aspek kehidupan manusia lainnya, tanpa terkecuali. Allah berfirman: "kami tidak melupakan dalam Al-Qur'an segala sesuatu" (QS. ). Oleh karenanya syariah Islam relevan untuk semua profesi apapun yang digeluti manusia di dunia ini.

Syumuliyah syariah Islam bermakna bahwa syariah ini ditujukan dan terapkan untuk semua jenis kelamin dan fase hidup manusia, laki dan perempuan, anak-anak, remaja, dewasa dan orang tua, masa sulit dan masa lapangnya. Walaupun terdapat penyikapan syariah yang berbedabeda pada usia dan kondisi tertentu dalam hidup manusia. Syariah Islam menyiapkan semua aturan dan konsep hidup untuk semua jenis kelamin manusia, usia dan fase kehidupannya secara adil, proporsional, seimbang dan menyeluruh. Allah berfirman: Allah telah menjadikan kalian dari lemah, tua..(QS. Lukman)

Syumuliyah syariah Islam bermakna mengatur semua dimensi diri manusia dalam hubungannya dengan Allah SWT (ibadah) dan mengatur serta membimbing dan membina seluruh aspek kehidupan manusia dengan manusia lainnya dan lingkungannya (muamalah) secara integral, seimbang dan bersinergi. Sehingga bidang ibadah tidak menjadi penghalang atau pengurang bidang muamalah, ibadah tidak mendistorsi dan menzalimi muamalah demikian pula sebaliknya. Keduanya berjalan secara harmonis dan bersinergi.

Syumuliyah syariah Islam juga bermakna, bahwa syariah Islam berlaku dan relevan untuk setiap tempat, waktu dan iklim. Ibadah, muamalah dan hukum Islam relevan dan berlaku kapan saja dan dimana saja, tanpa pembatasan dan diskriminasi. Tidak ada Negara atau bangsa yang lebih superior dalam syariah Islam dari bangsa lainnya. Tidak ada suku, ras dan bangsa tertentu yang dapat mengklaim bahwa ras, suku dan bangsanya lebih Islami, lebih baik dan lebih unggul dari bangsa dan suku lainnya di dunia ini. Karena Allah telah menetapkan bahwa: "Sesungguhnya

12 Yusuf Al-Qardhawi, Al-Khashais Al-Ammah Lil Islam, (Kairo: Maktabah Wahbah, 2003), hal 95

Khairan Muhammad Arif | Islam Rahmatan Lil Alamin Dalam Perspektif Sosial Dan Budaya 
yang paling mulia di antara kamu di sisi Allah ialah orang yang paling bertakwa".(QS. Al-Hujurat: 13). Jadi yang paling mulia adalah yang paling beriman, bertakwa, lebih konsisten terhadap syariah dan akidahnya.

\section{Realistis (al-waqi'iyah)}

Al-Waqi'iyah atau relaistis menurut Al-Qardhawi terkait karakteristik Islam bukan realistis dalam pengertian barat yang terkait dengan filsafat materialisme, yang tidak percaya pada sesuatu kecuali materi dan benda serta dapat dimanfaatkan dengan realistis pragmatis. Tapi yang dimaksud realistis dalam karakteritik Islam adalah "sifat syariat Islam yang mampu memahami kondisi alam sesuai dengan hakikat dan wujudnya yang dapat disaksikan oleh manusia, memahami dan mengerti bahwa kondisi hidup manusia adalah ciptaan Allah SWT dan berasal dari-Nya dan seterusnya" ${ }^{13}$.

Al-Waqi'iyah adalah karakter Islam yang bermakna bahwa Islam mengajarkan manusia untu mampu memahami dan memaklumi dengan realistis, bahwa manusia adalah ciptaan Allah, tidak ada zat lain yang menciptakannya, sesuai dengan kondisi riil dan ilmiah yang tidak terbantahkan oleh akal dan logika manapun di dunia. Bahwa seluruh makhluk termasuk manusia adalah hamba Allah, Dia yang menciptakan dan mengaturnya serta membimbingnya, kecuali yang ingkar dan memusuhi-Nya ${ }^{14}$.

Al-Waqi'iyah bermakna bahwa Islam adalah syariah yang mengerti dan memelihara keadaan fitrah dan kodrat manusia sebagai makhluk yang lemah dan terbatas, sehingga pemilik syariah (Allah SWT) memberikan kemudahan, keluwesan dan kebijakan yang mengakomodir kondisi riil manusia dalam melaksanakan syariah-Nya atau perintah dan laranganNya. Allah berfirman: "Allah hendak memberikan keringanan kepadamu, karena manusia diciptakan (bersifat) lemah". (QS. An-Nisa: 28).

Waqi'yah ajaran Islam dalam Ibadah telah melahirkan hukum-hukum keringanan (rukhshah), dan pemakluman (al-l'fa) dan sebagainya kepada manusia, ketika manusia tidak mampu melaksanakannya karena kondisikondisi tertentu. Allah tidak memaksakan puasa di bulan ramadhan, bagi mereka yang musafir, sakit dan melahirkan, karenan kondisinya yang lemah dan sulit, Allah tidak memaksakan zakat bagi muslim yang hartanya belum sampai nishab, Allah tidak memaksakan haji bagi mereka yang tidak mampu membiayai perjalanan dan bekal keluarganya, padahal itu semua adalah rukun Islam yang wajib, dimana Islam dibangun dengan nya. Sesuai ayat-ayat berikut: "Bulan Ramadan adalah (bulan) yang di dalamnya

13 Yusuf Al-Qardhawi, Al-Khashais Al-Ammah Lil Islam, hal 144

${ }^{14}$ Khairan Muhammad Arif, Moderasi islam, hal 225

Khairan Muhammad Arif | Islam Rahmatan Lil Alamin Dalam Perspektif Sosial Dan Budaya 
diturunkan Al-Qur'an, sebagai petunjuk bagi manusia dan penjelasanpenjelasan mengenai petunjuk itu dan pembeda (antara yang benar dan yang batil). Karena itu, barangsiapa di antara kamu ada di bulan itu, maka berpuasalah. Dan barangsiapa sakit atau dalam perjalanan (dia tidak berpuasa), maka (wajib menggantinya), sebanyak hari yang ditinggalkannya itu, pada hari-hari yang lain. Allah menghendaki kemudahan bagimu, dan tidak menghendaki kesukaran bagimu. Hendaklah kamu mencukupkan bilangannya dan mengagungkan Allah atas petunjukNya yang diberikan kepadamu, agar kamu bersyukur". (QS. Al-Baqarah: 185). "Makanlah buahnya apa-bila ia berbuah dan berikanlah haknya (zakatnya) pada waktu memetik hasilnya, tapi janganlah berlebih-lebihan. Sesungguhnya Allah tidak menyukai orang-orang yang berlebihan". (QS. Al-An'am: 141). "Dan (di antara) kewajiban manusia terhadap Allah adalah melaksanakan ibadah haji ke Baitullah, yaitu bagi orang-orang yang mampu mengadakan perjalanan ke sana. Barangsiapa mengingkari (kewajiban) haji, maka ketahuilah bahwa Allah Mahakaya (tidak memerlukan sesuatu) dari seluruh alam". (QS. Ali Imran: 97).

Waqi'iyah ajaran Islam dapat dilihat dengan jelas dalam keringanan hukum dari Allah SWT terhadap makanan dan minuman yang tadinya diharamkan bagi para mukallaf (objek hukum) seperti bangkai, babi, darah, khamar dan sebagainya. Namun ketika seorang muslim dalam kondisi emergensi atau darurat, yaitu kelaparan atau kehausan yang dapat mengancam jiwa dan fisiknya, dimana tidak ada makanan dan minuman selain yang haram, maka saat itu pula Allah membolehkan makan minum yang hara tersebut. Allah berfirman: "Sesungguhnya Dia hanya mengharamkan atasmu bangkai, darah, daging babi, dan (daging) hewan yang disembelih dengan (menyebut nama) selain Allah. Tetapi barangsiapa terpaksa (memakannya), bukan karena menginginkannya dan tidak (pula) melampaui batas, maka tidak ada dosa baginya. Sungguh, Allah Maha Pengampun, Maha Penyayang”. (QS. Al-Baqarah: 173).

Waqi'iyah ajaran Islam dapat dilihat dari dimensi muamalah, Allah SWT dan Rasul-Nya menjadikan semua syariah dalam bentuk muamalah, seperti ekonomi, bisnis, politik, pendidikan dan sebagainya, yang terkait hubungan antar masyarakat, Negara dan hubungan social lainnya, hukum asalnya adalah boleh. Hal ini untuk mengakomodir kondisi manusia. Kaidah figh yang terkenal dalam masalah ini menyebutkan "Hukum asal muamalah adalah boleh, sebelum ada dalil yang mengharamkannya".

Waqi'iyah ajaran Islam dapat juga dilihat dari segi penegakkan hukum, seorang yang membunuh orang lain dihukum qishas (setimpal), namun ketika keluarga korban memaafkannya, maka hukum atasnya diabaikan. Seorang pencuri di masa Umar bin Khattab RA, tidak dik-hukum karena kondisi orang yang mencuri tersebut sangat miskin dan benar-benar

Khairan Muhammad Arif | Islam Rahmatan Lil Alamin Dalam Perspektif Sosial Dan Budaya 
terbukti bahwa dia tidak punya makanan dan terdesak mencuri untuk melanjutkan hidupnya. Deikian sterusnya, syariah Islam adalah syariah yang realistis dan memelihar kondisi lemah dan terbatas manusia.

\section{Toleransi dan Memudahkan (as-samhah dan at-taisir)}

As-Samhah adalah memudahkan atau toleransi kepada orang lain ${ }^{15}$. Adapun at-taisir adalah kemudahan dan keringanan ${ }^{16}$. Ibnu Manzur hampir menyamakan makna as-samhah dan at-taisir yaitu kemudahan. Ibnu Asyur memaknai as-samahah adalah kemampuan berinteraksi dengan mudah dan proporsional, atau sikap pertengahan antara memudah-mudahkan dan mempersulit"17.

Ajaran Islam adalah ajaran yang sangat menghindari kesulitan bagi umat manusia dalam memahami dan mengimplementasikannya, sehingga tidak ada ranah syariah Islam yang sulit kecuali dimudahkan oleh Allah SWT. Ini bukan berarti semua ajaran syariah Islam seluruhnya mudah, karena itu tidak sesuai logika manusia, sebab sulit dan mudah dua hal yang ditakdirkan Allah SWT kepada makhluk-Nya, juga kepada syariatnya. Sebagaimana Allah mentakdirkan ada yang kaya dan ada yang miskin, siang dan malam dan sebagainya. Toleransi dan kemudahan yang dimaksud di sini adalah bahwa Allah SWT menjadikan ajaran Islam selalu membolehkan memilih yang termudah dan terbaik baik hamba-Nya bukan yang sulit dan buruk, Allah selalu membolehkan pilihan yang toleran dan tidak memberatkan bagi seluruh mukallaf. Allah SWT selalu menyertakan kemudahan kepada hamba-Nya ketika mereka menghadapi kesulitan dalam melaksanakan perintah-Nya dan dalam menghadapi kehidupan mereka sehari. Allah berfirman: "Allah menghendaki kemudahan bagimu, dan tidak menghendaki kesukaran bagimu”. (QS. Al-Baqarah: 185). "Allah tidak ingin menyulitkan kamu, tetapi Dia hendak membersihkan kamu dan menyempurnakan nikmat-Nya bagimu, agar kamu bersyukur". (QS. AlMaidah: 6). "Dia telah memilih kamu, dan Dia tidak menjadikan kesulitan untukmu dalam agama. (Ikutilah) agama nenek mo-yangmu Ibrahim. Dia (Allah) telah menamakan kamu orang-orang muslim sejak dahulu, dan (begitu pula) dalam (Al-Qur'an) ini, agar Rasul (Mu-hammad) itu menjadi saksi atas dirimu dan agar kamu semua menjadi saksi atas segenap manusia". (QS. Al-Haj: 78). "Maka sesungguhnya beserta kesulitan ada kemudahan. sesungguhnya beserta kesulitan itu ada kemudahan". (QS. AlInsyirah: 6-7).

\footnotetext{
15 Ibnu Manzur, Lisanul Arab,Vol 4, (Kairo: Daarul Hadits, 2003), hal 673

16 Ibnu Manzur, Lisanul Arab, vol 9, hal 452

17 At-Thahir bin Asyur, Maqashid As-Syari'ah Al-Islamiyah, (Kairo: Daar As-Salam, 2006), hal 58
}

Khairan Muhammad Arif | Islam Rahmatan Lil Alamin Dalam Perspektif Sosial Dan Budaya 
Dari Ibnu Abbas RA, Nabi SAW bersabda: "Agama yang paling dicintai oleh Allah adalah yang lurus dan mudah (Al-Hanafiyah As-Samhah)"(HR. Bukhari). Nabi SAW bersabda kepada Ali bin Abi Thalib dan Muaz bin jabal ke Yaman: "Kalian mudahkanlah dan jangan persulit umat, berikanlah kabar gembira dan jangan membuat mereka lari/menghindar"(HR. Bukhari). Nabi SAW bersabda kepada para Sahabatnya, ketika seorang Badui kencing di masjid: "Sesungguhnya aku diutus kepada kalian untuk memudahkan bukan untuk menyulitkan atau menyusahkan" (HR. Bukhari).

Oleh karenanya ajaran Islam sangat menghindari pemahaman radikal, keras dan intoleran kepada orang lain. Syariah Islam selalu menghendaki kemudahan dan pilihan-pilihan yang mudah, bukan pilihanpilihan yang sulit dan susah serta merepotkan. Inilah karakter utama syariah Islam sebagaimana ini adalah karakter utama wasathiyah Islam.

Demikian pula sifat toleran adalah karakter utama Islam. Nabi dan para Sahabat memahami dan mengamalkan syariah Islam dalam posisi toleran dan menerima perbedaan. Telah terjadi di antara para sahabat Nabi perbedaan pendapat tentang suatu masalah dalam syariah dan mereka saling toleran atas pendapat masing-masing (khilaf tanawu'), tanpa memaksakan pendapat kecuali pada masalah benar salah, petunjuk dan hidayah, halal dan haram atau yang dikenal dengan pebedaan yang bertentangan (khilaf mudhad). Para ahli sejarah seperti Ad-Zahabi, Ibnu Katsir, At-Thabari, As-Suyuthi dan lainnya menulis dalam sejarah mereka tentang perbedaan pandangan antara sahabat bahkan antara Nabi SAW dan sahabat.

\section{Antara Konstanitas dan Fleksibilitas (as-tsawabit dan al- mutaghayirat)}

Karakter terakhir dari ajaran Islam ini adalah as-tsawabit dan almutaghayirat, yaitu karakter ajaran Islam yang terklasifikasi dengan indah dan penuh hikmah dan rahasia tinggi dari Allah, ajaran islam yang tergolong konstan ajeg dan abadi tidak akan pernah berubah, seperti seluruh jenis rukun iman dan rukun Islam. Juga ajaran-ajaran pokok akhlak serta hal-hal yang telah diharamkan oleh Allah secara pasti (qath'iy) adalah tsawabit yang tidak menerima ijtihad dan pembaruan.

Ajaran Islam ada juga yang tergolong mutaghayirat yaitu semua hal yang terkait dengan sarana dan prasarana, motode dan srategi, media dan alat, cara dan teknik selain pokok agama (ushul ad-din), semuanya adalah mutaghayirat yang dapat meyesuaikan tempat dan waktu, fleksibel sesuai dengan kondisi manusia dan lingkungannya. Sehingga dengan karakter ini, Islam tetap menjadi ajaran yang paling orisinil dan autentik, dalam waktu

Khairan Muhammad Arif | Islam Rahmatan Lil Alamin Dalam Perspektif Sosial Dan Budaya 
yang sama ajaran-ajaran Islam juga relevan dan sesuai untuk setiap zaman dan tempat ${ }^{18}$.

\section{Kehidupan Sosial Budaya dan Dimensinya}

Kehidupan Sosial adalah salah satu ranah kehidupan manusia yang paling penting yang harus dikenal dan ketahui oleh manusia, karena manusia adalah makhluk social. Interaksi manusia dengan kehidupan atau lingkungan social adalah salah satu kebutuhan utama manusia.

Para ahli mendefinisikan kehidupan social dengan interaksi dan kehidupan bersama antar manusia karena kesamaan kepentingan dan tujuan, sebagaimana yang jelaskan oleh Ibnu Qayim Al-Jauziyah "Bahwa berkumpul, berinteraksi, bersatu adalah ciri manusia, sehingga dari sinilah dikenal kata Ummat, karena mereka adalah kumpulan manusia yang bersatu karena agama yang satu dalam suatu waktu"19. John Dewey (18591952) "Kehidupan social adalah berkumpulan, saling merasakan dan berserikat dalam suatu tujuan dan kepentingan serta saling tulus dalam mencapai tujuan umum" 20 . Kehidupan social atau lingkungan social dewasa ini dibagi oleh para ahli menjadi beberapa dimenasi atau jenis, diantaranya: Keluarga, Sekolah, Tempat kerja, Tempat Ibadah, Masyarakat dan Media massa.

Adapun budaya menurut Edward Taylor adalah "Konsep keseluruhan tentang sesuatu yang meliputi pengetahuan, ideology, seni, akhlak, hukum, adat istiadat, kompetensi-kompetensi yang dimiliki oleh manusia sebagai salah satu anggota masyarakat". Jadi dimensi budaya adalah: Pengetahuan, Ideologi, Akhlak dan budi pekerti, IImu Pengetahuan, Seni dan sains, Bahasa, Hukum dan Adat Istiadat.

Dimensi-dimensi budaya di atas dapat diwarnai oleh agama dan ideology terentu. Sejarah membuktikan bahwa silih bergantinya budaya di dunia dipengaruhi oleh agama dan ideology yang berpengaruh di dunia pada saat itu. Budaya atau tsaqafah ini dibentuk bukan dalam waktu yang singkat tapi dalam waktu yang panjang. Para ahli mengatakan bahwa sesuatu dapat disebut budaya, apabila berlangsung lama, disepakati dan bermanfaat bagi manusia.

\footnotetext{
18 Khairan Muhammad Arif, Moderasi Islam, hal 230

19 Khairan Muhammad Arif, Al-Ara At-Tarbawiyah indal Imam Ibnu Qayim Al-Jauziyah (Kairo: Liga Arab, 2005), Hal 95

20 Khairan Muhammad Arif, Moderasi Islam, hal 230
}

Khairan Muhammad Arif | Islam Rahmatan Lil Alamin Dalam Perspektif Sosial Dan Budaya 


\section{Implementasi Islam rahmatan lilalamin dalam kehidupan Social Budaya}

\section{Implementasi rahmatan lil alamin dalam Kehidupan Sosial}

Dalam Islam dimensi lingkungan social manusia yang sangat berpengaruh dalam kehidupan seseorang adalah lingkungan keluarga, karena keluarga adalah cikal bakal lahirnya manusia dan tempat mereka hidup dan beradaptasi pertama kali. Karenanya Rasulullah saw bersabda:

"Setiap anak lahir dalam keadaan sesuai fitrahnya (suci), maka kedua orag tuanyalah yang menjadikannya Yahudi, Majusi atau Nashrani" (HR. Muslim).

Oleh karena itu Islam sangat memperhatikan lingkungan keluarga dalam mendidik anak, membangun karakter dan akhlak serta membentuk keperibadian manusia. Sehingga Allah swt mewajibkan menjaga dan mendidikan keluarga shaleh dan menjadikannya bagian penting dalam ajaran Islam setelah menjaga diri sendiri. Allah berfirman:

"Wahai orang-orang beriman, jagalah dirimu dan keluargamu dari api neraka” (QS. At-Tahrim: 6).

Nabi saw sangat memperhatikan dan sangat tegas memberi himbauan dan memberikan teladan agar umat Islam yang rahmatan lilalamin ini memberikan cinta dan kasih sayang kepada keluarga, isteri dan anak. Nabi saw bersabda: "Sebaik-baik kalian adalah orang yang paling baik dan mencintai keluarganya dan aku adalah orang yang paling baik dan mencintai keluargaku"(HR. Tirmidzi dan Ibnu Majah).

Adapun Implementasi Nilai-nilai Rahmatan Lil alamin dalam kehidupan social lainnya seperti sekolah, masyarakat, Tempat Ibadah dan tempat kerja serta Media Massa, maka islam telah memberikan gaiden dan prinsip-prinsip mulia dan abadi dalam Al-Qur'an, Hadits dan praktek hidup Nabi saw dan sahabat sangat kaya dan implementatif dalam hal ini.

Diantara gaiden dan prinsip-prinsip islam rahmatan lilalamin dalam masalah social selain keluarga dapat dilihat sebagai berikut:

a. Interaksi social antar manusia yang majemuk, bersuku-suku dan berbangsa, harus dibangun berdasarkan prinsip saling mengenal (ta'ruf) antara satu dengan yang lain, namun yang paling mulia adalah yang bertakwa. (QS. Al-Hujuraat: 13)

b. Kehidupan social harus dibangun berdasarkan prinsip saling tolong menolong dalam kebaikan dan hal positif bukan dalam keburukan dan hal negative, baik di kantor, di masyarakat umum, media maupun dalam sarana ibadah. Allah berfirman: "Saling tolong menolonglah kalian

Khairan Muhammad Arif | Islam Rahmatan Lil Alamin Dalam Perspektif Sosial Dan Budaya 
dalam kebaikan dan takwa dan jangan saling tolong menolong dalam dosa dan permusuhan" (QS. Al-Maidah: 2)

c. Interaksi social harus dibangun dalam bingkai kasih sayang dan lemah lembut, agar manusia saling mencintai, menghormati dan bersatu, ini tidak hanya diimplementasikan dalam masjid, majelis taklim, tepai juga dalam kehidupan kerja, pendidikan dan media massa (QS. Ali Imran: 159)

d. Keputusan yang bersifat social kemasyarakat dan bernegara harus berdasarkan syura, sehingga melahirkan keputusan yang baik, berkualitas dan lebih sempurna (QS. Ali Imran: )

e. Untuk menjaga kehidupan masyarakat yang tentram dan aman dari isu hoax dan adu domba, harus dibangun sikap tabayyun atau klarifikasi dan cek and recek terhadap sumber informasi yang menyebar di kalangan masyarakat (QS. Al-Hujurat: 6)

f. Kehidupan social yang baik dan damai adalah menghindari saling meremehkan dan melecehkan antar anggota masyarakat, suku dan bangsa, karena boleh jadi yang diremehkan lebih baik dari kelompok yang meremehkan (QS. Al-Hujarat: 11)

g. Anggota masyarakat harus menjauhi praduga negatif dan kecurigaan yang berlebihan pada anggota masyarakat lainnya, sebaliknya harus dibangun sikap positif thinking (Husnu Dzon) kepada pihak lain, agar tercipta kedamaian dan ketentraman dalam masyarakat (QS. Al-Hujurat: 12)

h. Kehidupan social harus terbebas dari sikap saling benci dan saling bermusuhan, karena sikap perbuatan ini sama dengan memakan bangkai saudaranya sendiri, baik dalam lingkungan social bertetangga, tempat kerja maupun di media massa (QS. Al-Hujurat: 12)

i. Dalam masyarakat Muslim ditetapkan bahwa mereka adalah saling bersaudara sepenanggungan, bila terjadi gesekan antara mereka harus segera didamaikan, sehingga tercipta ukhuwah Islamiyah yang kuat (QS. Al-Hujurat: 10)

j. Dalam kehidupan masyarakat yang majemuk dan khususnya dalam Muslim harus dibangun sikap saling memaafkan antar individu masyarakat, bahkan saling meminta ampunkan dosa kepada Allah swt, baik dilingkungan kerja, ibadah ataupun di media massa (QS. Ali Imran: 159).

\section{Implementasi Nilai Rahmatan Lil alamin dalam kehidupan budaya}

Bila dilihat dari dimensi budaya di atas, maka islam rahmatan lil alamin telah terwujud dalam dimensi pengetahuan, bahasa, ideology, akhlak, Hukum, seni dan sebagainya. Islam selama tujuh abad (Abad 7-14 Masehi) telah menyumbangkan nilai-nilai budaya yang luar biasa. Hal ini bisa dilihat dari konsep Al-Qur'an dan As-Sunnah serta kehidupan Nabi, sahabat dan

Khairan Muhammad Arif | Islam Rahmatan Lil Alamin Dalam Perspektif Sosial Dan Budaya 
para Tabi'in, juga fakta yang tertulis sepanjang masa dan peniggalan serta karya-karya fenomenal dalam peradaban Islam yang mulia dan tinggi.

\section{a. Rahmatan lil alamin dalam IImu Pengetahuan}

Ilmu Pengetahuan sebagai dimensi utama sebuah budaya, telah memperlihatkan bagaimana ajaran Islam yang rahmatan lil alamin, ketika Allah swt, mengangkat derajat orang berilmu sama dengan derjat orang yang beriman, bahkan IImu adalah prasyarat utama keimanan seorang hamba. Allah berfirman: "Allah mengangkat derajat orang beriman diantara kalian dan orang berilmu beberapa derajat" (QS. Al-Mujadilah: 11)

Allah swt juga menetapkan bahwa orang yang paling takut kepada Allah, adalah orang yang paling berilmu. Rasa takut dalam Islam adalah sifat dan akhlak paling tinggi seorang hamba kepada Allah swt. Semakin takut seorang hamba semakin memiliki budaya akhlah dan adab paling tinggi kepada Allah swt. Allah berfirman: "Sesungguhnya orang yang paling takut kepada Allah adalah para hambanya yang Ulama” (QS. Fathir: 12)

Bahkan Rasulullah saw, berani mengklaim bahwa sebaik-baik manusia adalah hamba Allah yang berilmu, bagaikan posisinya dengan umatnya yang paling rendah, beliau bersabda: "Sesungguhnya keutamaan seorang alim atas seorang abid (ahli ibadah) seperti keutamaan antara aku dan orang paling rendah di antara kalian" (HR. Tirmidzi).

Islam melarang melakukan sesuatu tanpa IImu, sehingga menimbulkan masalah dan permusuhan serta kekerasan, Allah berfirman: "Dan janganlah kamu mengikuti sesuatu yang tidak kamu ketahui, karena pendengaran, penglihatan dan hati nurani semua itu akan diminta pertanggungjawabannya” (QS. Al-Isra: 36)

\section{b. Rahmatan lil alamin dalam Bahasa}

Bahasa yang merupakan dimensi utama dalam sebuah budaya, juga menunjukkan bahwa islam memiliki bahasa agama yang universal dan lembut, kosa katanya paling banyak dan paling sopan dan indah di dunia, yaitu bahasa arab. Allah menjelaskan bahwa bahasa Araba adalah tinggi dan jelas. "padahal Al-Qur'an ini adalah dalam bahasa Arab yang jelas." (QS. An-Nahl: 103)

Al-Qur'an selain menggunakan bahara Arab yang indah dan lembut penuh kasih sayang, juga memberikan gaiden dan prinsip kepada umatnya agar memakai bahasa dan kata-kata yang tepat, jelas lembut kepada orang lain sebagai nilai rahmatan lil alamin. Allah berfirman: "Wahai orang-orang

Khairan Muhammad Arif | Islam Rahmatan Lil Alamin Dalam Perspektif Sosial Dan Budaya 
beriman bertakwalah kepada Allah dan ucapkanlah kata-kata yang benar." (QS. Al-Ahzab: 70)

Islam melarang semua ucapan dan kata-kata yang tidak baik dan negative, apalagi menimbulkan permusuhan. Nabi saw bersabda: "Muslim itu adalah ketika orang lain selamat dari lidah dan lisannya." (HR. Bukhari dan Muslim)

\section{c. Rahmatan Lil alamin dalam Akhlak}

Dalam Akhlak dan perilaku sehari-hari, Islam juga mewajibkan kepada umatnya untuk berakhlak mulia. Akhlak paling mulia yang pernah dioraktekkah oleh manusia sepanjang sejarah adalah akhlak Nabi Muhammad saw, sesuai rekomendasi Allah swt: "Sungguh engkau Muhammad berada pada puncak akhlak yang paling tinggi.”(QS. Al-Qalam: 4)

Bahkan Nabi saw menjelaskan bahwa manusia yang paling sempurna imannya dalah yang paling berakhlak baik, dan beliau diutus sebagai Nabi adalah dengan misi utama memperbaiki akhlak mulia. "Iman mukmin yang paling sempurna adalah yang paling baik akhlaknya.” (HR. Abu Daud)

\section{d. Rahmatan Lil alamin dalam adat istiadat}

Menurut Abdul Wahab Khallaf, adat adalah kebiasaan manusia yang terus dilakukan berupa ucapan, perbuatan atau yang ditinggalkan. Para Ulama menyepakati bahwa adat Istiadat tidak boleh melahirkan kerusakan, sebaliknya adat istiadat yang baik dan mengandung maslahat serta tidak betentangan dengan AI-Qur'an dan hadits atau syari'at, maka adat istiadat tersebut dapat menjadi hokum. العادة محكمة Adat menjadi hokum. Diantara adat keiasaan masyarakat modern yang telah menjadi hokum dan dibolehkan oleh syara' adalah: Jual beli suatu barang di toko tanpa melafadzkan akad antara penjual dan pembeli, tapi langsung dibayar lewat transfer atau memasukan uang pada mesin dan sebagainya.

\section{KESIMPULAN}

Islam rahmatan lil alamin adalah Islam yang sesuai dengan fitrah manusia, islam yang membawa kasih sayang, cinta bukan kebencian, kedamaian bukan permusuhan. Islam rahmatan lilalamin adalah Islam yang membawa kemudahan bukan kesulitan dan membawa solusi kehidupan bukan masalah dan pertikaian.

Islam rahmatan lilalamin adalah ajaran Allah SWT yang paling mengetahui seluk beluk manusia, karenanya dia menjadi ajaran dan ideology yang menyelamtkan manusia, mengajarkan saling meghormati

Khairan Muhammad Arif | Islam Rahmatan Lil Alamin Dalam Perspektif Sosial Dan Budaya 
dan saling toleransi, selama menghasilkan maslahat bagi manusia. Islama rahmatan lilalamin adalah Islam universal dan komprehensif, harus diimplementasikan dalam semua dimensi hidup manusia termasuk kehidupan social budaya.

Dalam kehidupan sosial, islam menjadi rahmat dalam kehidupan keluarga, lingkungan pendidikan, Masyarakat, lingkungan kerja, ibadah dan media massa. Dalam ranah Budaya, islam menjadi rahmat dalam ilmu, sains, bahasa, akhlak ideology dan adat istiadat.

\section{DAFTAR PUSTAKA}

Abu Hamid Al-Ghazali, Al-Mustashfa min IImi Al-Ushul, Riyadh: Daar Al-Mihan, tt

Abu Ishaq As-Syatibi, Al-Muwafaqat fii Ushul As-Syariah, Kairo: almaktabah at-taufiqiyah, 2003

Ar-Raghib Al-Ashfahani, Mu'jam Mufradat Li Alfadzil Qur'an, Beirut: Daar Al-Kutub Al-IImiyah, 2013

At-Thahir bin Asyur, Maqashid As-Syari'ah Al-Islamiyah, Kairo: Daar As-Salam, 2006,

Ibnu Jarir At-Thabari, Tafsir At-Thabari, Kairo: Maktabah AtTaufiqiyah, 2004

Ibnu Manzur, Lisanul Arab, Kairo: Daarul Hadits, 2003

Ismail Ibnu Katsir, Tafsir Ibnu Katsir, Beirut: Daar Al-Fikr, 1994

Khairan Muhammad Arif, Al-Ara At-Tarbawiyah indal Imam Ibnu Qayim Al-Jauziyah Kairo: Liga Arab, 2005

Khairan Muhammad Arif, Moderasi Islam Telaah Komprehensif Wasathiyah Islam dalam Perspektif Al-Qur'an dan As-Sunnah ,enuju Islam Rahmatan Lil Alamiin, Jakarta: Pustaka Ikadi, 2020

Sayid Qutb, Fi Dzilal Al-Qur'an, Kairo: Dar Syuruq, 1995

Yusuf Al-Qardhawi, Al-Khashais Al-Ammah Lil Islam, Kairo: Maktabah Wahbah, 2003

Khairan Muhammad Arif | Islam Rahmatan Lil Alamin Dalam Perspektif Sosial Dan Budaya 